\title{
THE NEST PREDATOR ASSEMBLAGE FOR SONGBIRDS IN MONO LAKE BASIN RIPARIAN HABITATS
}

\author{
Quresh S. Latif 1,2 , Sacha K. Heath ${ }^{3,4,5}$, and Grant Ballard ${ }^{3,4}$
}

\begin{abstract}
Because nest predation strongly limits avian fitness, ornithologists identify nest predators to inform ecological research and conservation. During 2002-2008, we used both video-monitoring of natural nests and direct observations of predation to identify nest predators of open-cup nesting riparian songbirds along tributaries of Mono Lake, California. Video cameras at 50 nests of 3 songbird species and direct observations of additional nests confirmed 10 distinct nest-predator species and suggested one additional species. Video-monitored nests experienced reduced predation rates, and video observations mainly captured nestling predation, even though predation rates were higher for nonvideo-monitored nests during the egg period. These findings suggest cameras may have missed some predators. By supplementing video records with field observations, we reduced the likelihood of excluding species from our predator list that substantially impact fitness due to camera-related biases. No single predator species emerged as predominantly important for shaping avian fitness. Nevertheless, we frequently observed garter snakes (Thamnophis sp.) depredating nestlings and Brown-headed Cowbirds (Molothrus ater) depredating eggs. Corvids and rodents were also identified as potentially frequent groups of nest predators. Video cameras recorded partial predation by 5 predator types, as well as several cases in which nests were visited by multiple predators. Finally, 6 of 7 predators that were video-recorded depredating artificial nests were species also documented depredating natural nests. These observations verify the relevance of artificial-nest data for further study of these predators.
\end{abstract}

Resumen.-Debido a que la depredación de nidos limita de manera contundente la adecuación de las aves, los ornitólogos identifican a los depredadores de nidos para documentar la investigación ecológica y la conservación. Durante 2002-2008, utilizamos el monitoreo por video de nidos naturales y observaciones directas de la depredación para identificar a los depredadores de nidos de ruiseñores ribereños que realizan nidos abiertos en los afluentes del Lago Mono en California. Las cámaras de video en 50 nidos de 3 especies de ruiseñores y las observaciones directas de nidos adicionales confirmaron 10 especies diferentes de depredadores de nidos y sugirieron 1 especie adicional. Los nidos monitoreados por video experimentaron tasas de depredación reducidas y las observaciones de video capturaron principalmente la depredación de las crías, a pesar de que las tasas de depredación fueron más elevadas en los nidos que no estaban monitoreados por video durante el período de huevos. Estos descubrimientos sugieren que las cámaras pueden haber omitido algunos depredadores. Al complementar los registros de videos con las observaciones de campo, redujimos la posibilidad de excluir especies de nuestra lista de depredadores que impactan de manera sustancial la adecuación, debido a las parcialidades de la cámara. Ninguna especie individual de depredador surgió como predominantemente importante en la determinación de la adecuación de las aves. Sin embargo, con frecuencia observamos culebras de agua (Thamnophis sp.) depredando a las crías y Garrapateros de cabeza marrón (Molothrus ater) depredando a los huevos. Córvidos y roedores también se identificaron como grupos posiblemente frecuentes de depredadores de nidos. Las cámaras registraron una depredación parcial realizada por 5 tipos de depredadores, así como también varios casos en los cuales los nidos recibían la visita de múltiples depredadores. Finalmente, 6 de 7 depredadores registrados por las cámaras mientras depredaban nidos artificiales eran especies que también se documentaron mientras depredaban nidos naturales, lo que comprueba la relevancia de los datos recogidos de nidos artificiales para estudios adicionales de estos depredadores.

Nest survival is an important component of avian fitness, and predation is the main cause of nest failure for most terrestrial bird species (Ricklefs 1969, Clark and Martin 2007). Consequently, nest predation strongly influences the evolution and ecology of birds (Lima 2009, Saether and Bakke 2000) and is therefore a concern for conservationists and managers (Martin 1989, Sperry et al. 2009). Studies of nest predation often document environmental correlates of predation rates (Filliater et al. 1994, Wilson and Cooper 1998, Aguilar et al. 2008). Environmental features correlate with predation rates in individual systems, however, they

${ }^{1}$ Biology Department, University of California, Riverside, 900 University Ave., Riverside, CA 92521. 2Present address: Roch
E-mail: qlatif@fs.fed.us

${ }^{3}$ PRBO Conservation Science, 3820 Cypress Drive \#11, Petaluma, CA 94954

${ }^{4}$ Oikonos, Box 1932, Benicia, CA 94510

5Present address: Ecology Graduate Group, University of California, Davis, 1 Shields Ave., Davis, CA 95616 
are not useful for predicting predation probability across systems (Lahti 2009), in part because predators differ among systems. Therefore, identification of nest predators is an important step towards understanding the factors that determine nest predation risk and ultimately avian fitness (Thompson 2007).

Video cameras are an especially effective tool for identifying nest predators. Video records are valuable because they reliably link individual predator groups with specific types of nest predation, such as discrimination of egg predators from nestling predators (e.g., Liebezeit and George 2002a, Stake and Cimprich 2003). Video footage also allows identification of predators that partially depredate nests (Lariviere and Messier 1997, Small 2005). Partial depredation can have different implications for avian fitness than does complete predation. Despite their desirability, however, video studies may not generate comprehensive nest-predator lists for individual systems for at least 5 reasons: (1) the expense of recording equipment limits sample sizes; (2) video-monitored nests tend to experience reduced predation rates, perhaps due to neophobic or camera-shy species (Richardson et al. 2009), further reducing sample sizes; (3) small samples may lead to biased sampling of sites or habitats that favor some species over others; (4) delayed camera deployment may reduce the likelihood of recording predation, particularly early in the nesting cycle when predation rates are often highest (Dinsmore et al. 2002, Coates and Delehanty 2010; also see discussion by Pietz and Granfors 2000); (5) if camera deployment is delayed, egg predators may be underrepresented in video records. Given such biases, supplementing video records with direct observations of predation recorded by field workers could provide additional opportunities for predator identification; however, direct observations likely favor conspicuous and diurnal nest predators. Nevertheless, data from direct observations could identify or suggest species missing from video records, allowing researchers to fill potential gaps in nest-predator lists for particular systems.

Artificial nests provide another tool for studying nest predation. Artificial nests have been widely used because of their minimal cost and tremendous potential for facilitating experimental control (Major and Kendal 1996, Weidinger 2002). Predators depredate artifi- cial nests at different relative and absolute frequencies than they do natural nests (Thompson and Burhans 2004), so artificial-nest predation rates may not reflect natural rates (Moore and Robinson 2004). Nevertheless, artificial nests can illuminate important aspects of the ecology and behavior of predators that do depredate them (Schmidt and Whelan 1999, Schmidt et al. 2001, Santisteban et al. 2002), yielding insight into the potential mechanisms driving natural predation patterns (Latif et al. $2011,2012)$. To verify the relevance of artificial-nest data in order to study particular mechanisms or predators, artificial-nest predators should be identified and confirmed as predators of natural nests.

We identified predators of riparian songbird nests along tributaries of Mono Lake, California, a mid-elevation system (ca. 2000 m) located on the western edge of the Great Basin. We focused on open-cup nesting species, which are especially vulnerable to predation and represent a substantial portion of riparian bird diversity, and thus North American avian diversity in general (Knopf et al. 1988, Ohmart 1994, Saab et al. 1995). We used video recordings to identify nest predators and to document specific types of predation (i.e., egg vs. nestling, partial vs. complete) carried out by individual predators. Video cameras also recorded additional predator behaviors that may further our understanding of predatorprey interactions. Video data from natural nests were scarce, and nest survival analyses revealed significant differences in predation rates and the timing of predation between video-monitored and traditionally monitored nests, suggesting possible camera-related biases. We therefore supplemented these data with direct observations of nest predation made by field workers. Finally, we used video cameras to identify predators of artificial nests, to verify relevance of artificial-nest data, and to support separate studies of mechanisms underlying predation risk for Yellow Warblers (Setophaga petechia; Latif et al. 2011, 2012, in press).

\section{Methods \\ Study System}

We identified nest predators in riparian habitats along the lower reaches of 4 tributaries of Mono Lake, Mono County, California 
TABLE 1. Distribution of video-monitoring effort at songbird nests in Mono Lake Basin riparian habitats. Cameras were deployed at Yellow Warbler (Setophaga petechia; YEWA), Song Sparrow (Melospiza melodia; SOSP), and Lazuli Bunting (Passerina amoena; LAZB) nests. Subscripts denote at which of 3 sites (Lee Vining [L], Rush [R], and Mill creeks $[\mathrm{M}]$ ) cameras were deployed in each year.

\begin{tabular}{lcccc}
\hline & \multicolumn{3}{c}{ Nests monitored } & \\
\cline { 2 - 3 } Year & YEWA & SOSP & LAZB & Cameras \\
\hline 2002 & $3_{\mathrm{R}, \mathrm{M}}$ & $1_{\mathrm{L}}$ & $1_{\mathrm{L}}$ & 1 \\
2003 & $12_{\mathrm{L}, \mathrm{R}}$ & $16_{\mathrm{R}, \mathrm{L}}$ & & 6 \\
2004 & $14_{\mathrm{R}}$ & & 5 \\
2007 & $1_{\mathrm{R}}$ & & $2^{\mathrm{a}}$ \\
2008 & $2_{\mathrm{R}}$ & & $2^{\mathrm{a}}$ \\
\hline aCameras in $2007-2008$ were also deployed at artificial nests.
\end{tabular}

(1951-2070 m, 37 $56^{\prime} \mathrm{N}, 119^{\circ} 04^{\prime} \mathrm{W}-38^{\circ} 04^{\prime} \mathrm{N}$, $119^{\circ} 09^{\prime}$ W). Rush Creek, Lee Vining Creek, and Mill Creek have historically endured decades of water diversions and livestock grazing (Stine et al. 1984, Stine 1995), and these tributaries are currently undergoing varying levels of ecological restoration (Fitzhugh and Richter 2004). Wilson Creek is a partially artificial stream channel that has been managed as an irrigation ditch and has received enhanced perennial flow since the early 1900s. Willow (Salix exigua, Salix lucida, and Salix lutea) and black cottonwood (Populus balsamifera trichocarpa) dominate the streamside vegetation. Secondarily, Woods' rose (Rosa woodsii) grows either in contiguous monotypic stands or is interspersed within the willow/cottonwood understory. Big sagebrush (Artemisia tridentata) and antelope bitterbrush (Purshia tridentata) dominate the surrounding landscape and encroach into the riparian corridor due to historic fluctuations in water levels and the spatial extent of riparian corridors (Heath et al. 2006a, 2006b, 2006c, 2006d). Various songbird species nest along these tributaries mainly from mid-May to mid-August. Song Sparrows (Melospiza melodia) and Yellow Warblers are 2 of the most populous of these species (Heath et al. 2006a, 2006b, 2006c, 2006d).

\section{Video Monitoring of Natural Nests}

Video cameras $(49 \mathrm{~mm}$ wide $\times 70-84 \mathrm{~mm}$ long) were either wired or wirelessly connected to 24-h time-lapse video cassette recorders (VCRs; allowed $24 \mathrm{~h}$ of footage to be recorded on an 8-h VHS tape). Cameras could record in the infrared spectrum and were equipped with red/infrared illumination, allow- ing identification of nocturnal predators. One camera (manufactured by Sandpiper Technologies, Manteca, CA) illuminated at $940 \mathrm{~nm}$, and the remaining cameras (purchased from various security camera retailers) illuminated at 700-800 $\mathrm{nm}$ (although within the visible spectrum, nocturnal predation events were recorded with these cameras). We mounted cameras $<1 \mathrm{~m}$ from nests with an approximately 20-50-cm field-of-view centered on the nest, allowing a clear view of any nest visitors from the resulting video footage (nest contents were sometimes but not always visible). Camouflage-patterned duct tape covered cameras to reduce their visual conspicuousness. Battery solar-panel arrays powered recorders and cameras. We placed all additional equipment (other than cameras) $>10 \mathrm{~m}$ from the nest. When wired directly to cameras, VCRs were $\sim 10-30 \mathrm{~m}$ from nests. They were powered by either $122 \times 103-\mathrm{cm}$ solar arrays or $122 \times 152-\mathrm{cm}$ solar arrays coupled with either marine deep-cycle or sealed Concorde AGM batteries. Wireless video systems incorporated up to 4 cameras, each connected to a $94 \times 51-\mathrm{cm}$ solar panel with battery and transmitter (each transmitter was $<20 \mathrm{~cm}^{2}$ and mounted on a $\sim 1.5-\mathrm{m}$ pole) placed $10-30$ $\mathrm{m}$ from the nest camera. Nests monitored concurrently with cameras were never $<30 \mathrm{~m}$ from each other. Video images were transmitted to receivers (equal to the number of cameras) connected to a quad processor and VCR. These were placed $>100 \mathrm{~m}$ from all nests and powered by either of the larger battery solarpanel arrays also used to power the wired systems (described above).

We deployed cameras at natural nests from 18 May to 2 August, mainly during 2002-2004 (3 additional natural nests were monitored in 2007-2008; Table 1). Following video-monitored nest failures/successes, we continued redeploying cameras until no new nests were available.

We deployed cameras at 50 active songbird nests, which we found and monitored in conjunction with an all-species bird demography monitoring program (Heath et al. 2006a, 2006b, 2006c, 2006d). These nests included 33 shrub nests (32 Yellow Warbler and 1 Lazuli Bunting [Passerina amoena]; about 50-250 cm high) and 17 low-shrub or forb nests (all Song Sparrow nests; $<50 \mathrm{~cm}$ high; Table 1). When possible, we deployed cameras during the 
incubation stage $(n=34)$. Incubation-stage nests were often unavailable, however, in which case we deployed cameras during the nestling stage $(n=16)$. Camera deployment probably resulted in abandonment (no new eggs laid following deployment and/or abandonment within 2 days) in 3 cases when cameras were deployed during building (at 1 Yellow Warbler nest) and during laying (at 1 Yellow Warbler and 1 Song Sparrow nest); aside from these instances, laying- and building-stage deployments were not attempted. Cameras monitored nests in multiple years at multiple sites and in various microhabitats (e.g., both nests in willow and in Woods' rose were monitored). Nevertheless, we did not have enough cameras (Table 1) to distribute them evenly and thus ensure unbiased sampling with respect to spatial, temporal, and environmental factors. Camera deployment took about 2-10 min, during which parents usually remained off the nest. We watched nests using remote monitors and shifted cameras farther from the nest if parents did not resume nest attendance activities (incubation, feeding young, or brooding) within 20 min of camera deployment.

We changed tapes daily, which allowed us to record continuously. A handheld monitor allowed remote viewing of nests, so unless camera angles were disturbed or nests appeared inactive, we only approached nests once in 4 days to record their contents (it was usually impossible to confirm precise nest contents remotely, because parents were often on the nests and because of camera angle). We immediately reviewed footage recorded between any 2 nest checks during which the number of eggs or nestlings was reduced to identify predators responsible for the change. We also reviewed all video footage obtained at natural nests to look for potential predator visits that had not resulted in clutch or brood losses. We considered an animal to have visited the nest if it entered the camera field-ofview and clearly directed its attention to the nest. For each visit made by an animal, we noted whether eggs or nestlings were depredated and whether depredation was partial or complete. We defined any animal other than the parents that destroyed eggs or nestlings as a predator, regardless of whether nest destruction was carried out to procure food. We considered any footage of a particular predator species within 2 hours at the same nest to be part of the same visit. We considered nests retaining only brood parasitic eggs or nestlings following a predation event to have been partially depredated.

\section{Analysis of Nest Survival and Timing of Nest Failure}

To evaluate bias attributable to nest-monitoring technique, we used logistic exposure models (Shaffer 2004b; fitted in R v. 2.13.1 using code provided by Shaffer 2004a) to estimate daily survival rates for Song Sparrow and Yellow Warbler nests with and without cameras during the egg and nestling stages. Each model contained Camera (video vs. non-video monitored), Stage (egg vs. nestling), and Camera $\times$ Stage interaction parameters. To control for biased sampling by cameras, each model also included a parasitism status parameter (scored during each check interval) and a Site $\times$ Year blocking parameter. Yellow Warbler models also included a nest substrate parameter describing differences in survival rates between nests in mesic (Salix spp. or Populus trichocarpa) and xeric (Rosa woodsii or Artemisia tridentata) shrub species (for relevance, see Latif et al. 2011).

We only included data from non-camera nests monitored at sites and in years when cameras were deployed (Table 1). When analyzing nest survival, we considered nests as failed when entire host (Song Sparrow or Yellow Warbler) clutches or broods were lost due to predation (includes instances of abandonment immediately following partial clutch predation). We excluded check intervals when nests were abandoned or when hosts discontinued incubation due to cowbird eggs hatching first, but we included data from nests prior to the intervals when they were abandoned. We calculated daily survival rates and standard errors for camera and non-camera nests during the egg and nestling periods, assuming average values for the remaining covariates (mean covariate values calculated across check intervals). We also translated daily rates into total nest survival rates for camera and noncamera nests $\left(\right.$ TSR $=D_{\text {DSR }}$ Egg Egg_period $\times$ $\mathrm{DSR}_{\text {Nestling Nestling_period; egg and nestling }}$ periods for Yellow Warbler were 13.2 and 9.8 days, respectively, and for Song Sparrow were 14 and 10.5 days, respectively; nest periods were calculated using unpublished data from the Mono Lake Basin). Standard errors for 
TSR were calculated using the delta method (Powell 2007). We calculated the variance inflation factor, $\hat{c}$, for each model (Burnham and Anderson 2002) to test model fit. Given lack of fit $(\hat{c}>1)$, we multiplied survival rate variances by $\hat{c}$.

\section{Direct and Indirect Observations Recorded by Field Workers}

From 1 May to 15 August 2000-2005, field workers visited each of 2 study plots along each of the 4 creeks $(n=8)$ approximately every other day (the local breeding season). From 1 May to 15 August 2006-2008, we visited one plot along Rush Creek nearly every day. Study plots encompassed 39, 30, 15, and 15 ha of riparian habitat on Rush, Lee Vining, Mill, and Wilson creeks. The 2006-2008 Rush Creek study plot encompassed 20 ha of riparian habitat. Observers were charged with the daily task of finding and monitoring nests and mapping all avian territorial individuals within their plots. In conjunction, they recorded all observations of predatory behaviors associated with nests and compiled these observations for each plot. We report direct observations of predation: predators either in the act of consuming/destroying eggs/nestlings at nests or carrying eggs/nestlings. We also report indirect observations of predation: fresh sign of a particular predator (e.g., pecked nestlings or an ejected but uneaten nestling and a newly laid cowbird egg) or the predator itself appearing at a nest during the same check interval in which the nest was depredated (within 4 days) without direct evidence of the predation event itself. We only report indirect observations when multiple lines of evidence implicated a particular predator type.

\section{Identification of Artificial-Nest Predators}

In 2007-2008, separate studies employed artificial nests to examine the mechanisms underlying egg predation patterns for Yellow Warblers along Rush Creek (Latif et al. 2011, 2012 , in press). In conjunction with this work, we used video cameras to identify predators of eggs from these artificial nests. Artificial nests consisted of inactive Yellow Warbler nests (collected previously from our study plots) each containing a real songbird egg (i.e., a Zebra Finch [Taeniopygia guttata] egg) and a clay egg. Songbird eggs in artificial nests were comparable in size (about $16 \times 12 \mathrm{~mm}$ ) to Yellow
Warbler eggs (about $17 \times 13 \mathrm{~mm}$ ). Video cameras monitored artificial nests until they were depredated (i.e., damage or removal of either egg) or for a maximum of $13 \mathrm{~d}$, which corresponds to the mean laying $(2.79 \mathrm{~d}, \mathrm{SE}=0.08)$ and incubation $(10.33 \mathrm{~d}, \mathrm{SE}=0.19)$ period for this Yellow Warbler population $(n=129$ nests, PRBO unpublished data). Artificial nests were monitored in sites previously used by Yellow Warbler or in sites characterized by microhabitat used by nesting Yellow Warblers (for details, see Latif et al. 2011, 2012). To verify the relevance of artificial-nest data, we considered the extent to which predators we observed depredating artificial nests were also observed depredating natural nests.

\section{RESUlTS}

Video Documentation of Nest Predators

Video cameras recorded 16 predator visits (recorded from 1 July-7 August) by at least 8 predator species to 11 natural nests (Table 2; 3 of these nests were visited multiple times and are described further below). Video cameras recorded 7 cases of nestling predation, 2 by garter snakes and 1 each by 5 other species. Three of 4 recorded cases of egg predation were carried out by Brown-headed Cowbirds (all females; hereafter referred to as cowbirds; Table 2). Three other species (cowbird, wren, and ermine) visited nests during the egg period, but only 2 (cowbird and wren) depredated any eggs (taxonomic names provided in Table 2).

Twelve of the 16 video-recorded predator visits resulted in either partial or no clutch/ brood loss (Table 2). Twenty-six of the 50 video-monitored nests were parasitized. All 3 cowbird predation events were recorded at previously parasitized nests. All resulted only in the loss of host eggs, and after one event, only cowbird eggs remained in the nest. One cowbird visited a nonparasitized Yellow Warbler nest on 27 June 2008 (one day before the nest fledged), but it did not depredate any of the nestlings. Three of 4 partial predation visits by non-cowbird predators resulted only in the loss of cowbird eggs/nestlings, although only one actually contained any host contents (one Song Sparrow nestling). A mouse (Peromyscus sp.) depredated one 10-day-old cowbird nestling just as the other nestling successfully fledged (color-banded nestling later observed 
TABLE 2. Video-recorded predator visits to natural nests by predation type (complete, partial, or no predation) in riparian habitat in the Mono Lake Basin, California, 2002-2008. Subscripts denote period of visit $(\mathrm{E}=\mathrm{egg}, \mathrm{N}=\mathrm{nestling})$ and nesting species (YEWA $=$ Yellow Warbler $[$ Setophaga petechia], SOSP $=$ Song Sparrow $[$ Melospiza melodia $]$, LAZB $=$ Lazuli Bunting [Passerina amoena]).

\begin{tabular}{|c|c|c|c|c|c|}
\hline Predator type & Taxonomic name & None & Partial & Complete & Total \\
\hline Brown-headed Cowbird & Molothrus ater & $1_{N, Y E W A} ; 1_{E, Y E W A}$ & $3_{\mathrm{E}, \mathrm{SOSP}}$ & & 5 \\
\hline Steller's Jay & Cyanocitta stelleri & & & $1_{\mathrm{N}, \mathrm{YEWA}}$ & 1 \\
\hline Wren sp. & $\begin{array}{l}\text { Troglodytes aedon or } \\
\text { Thyomanes bewickii }\end{array}$ & & $1_{E, \text { LAZB }}$ & & 1 \\
\hline Raccoon & Procyon lotor & & & $1_{\mathrm{N}, \mathrm{SOSP}}$ & 1 \\
\hline Ermine & Mustela erminea & $1_{\mathrm{E}, \mathrm{SOSP}}$ & $1_{\mathrm{N}, \text { SOSP }}$ & & 2 \\
\hline Deer mouse & Peromyscus maniculatus & & $1_{\mathrm{N}, \text { SOSP }}$ & & 1 \\
\hline Garter snake & $\begin{array}{l}\text { Thamnophis sirtalis fitchi } \\
\text { or T. elegans elegans }\end{array}$ & $1_{\mathrm{N}, \mathrm{YEWA}}$ & $1_{\mathrm{N}, \mathrm{SOSP}}$ & $1_{\mathrm{N}, \mathrm{YEWA}}$ & 3 \\
\hline Gopher snake & $\begin{array}{l}\text { Pituophis melanoleucus } \\
\quad \text { deserticola }\end{array}$ & $1_{\mathrm{N}, \operatorname{SOSP}}$ & & & 1 \\
\hline Unidentified snake & & & $1_{\mathrm{N}, \mathrm{YEWA}}$ & 1 & \\
\hline
\end{tabular}

$<50 \mathrm{~m}$ from nest) immediately upon the mouse's arrival. Three visits, 2 by snakes and one by an ermine, resulted in no predation, although it is possible that the same ermine depredated the same nest subsequently (described further below). One Song Sparrow nestling fledged $75 \mathrm{~s}$ prior to the arrival of a gopher snake into the camera's field of view, and a garter snake visited a Yellow Warbler nest the day after all chicks had fledged.

We recorded multiple visits by different predators at 3 nests (all Song Sparrow). At one nest, one day after a Song Sparrow and a cowbird nestling hatched, a garter snake visited and depredated the cowbird nestling but left the Song Sparrow alive. A gopher snake visited the same nest 9 days later, $75 \mathrm{~s}$ after the Song Sparrow chick fledged (probably forcefledged by the snake). At $05: 10$ on 20 June 2003, a second nest was visited by an ermine, which left at least 3 Song Sparrow eggs and 3 cowbird eggs (counted 2 days prior to this event; nest contents were not completely visible on screen) intact. At 05:16 on the same day, a cowbird visited this nest and presumably laid a fourth cowbird egg. At 16:24, the incubating female removed an egg (possibly one damaged during the cowbird's earlier visit). At 18:19, a cowbird (possibly the same individual) visited again. The cowbird thrust its bill into the nest several times, picked up and dropped one egg, and then removed another egg. The Song Sparrow immediately returned, consumed the contents of the damaged eggs, removed one at 18:21, and removed a second at 19:01, after which 4 cowbird and zero host eggs remained (counted 2 days following this event). Finally, at 05:04 on 30 June, an ermine (possibly the same one) visited the same nest and depredated a cowbird nestling, leaving a second cowbird nestling to die of unknown causes by the next morning. A cowbird visited a third nest during incubation at 12:28 on 24 July 2003 and removed one host egg, leaving another host egg and 2 cowbird eggs intact. Two cowbird nestlings hatched and survived until 01:33 on 7 August (age $=10$ days) when a deer mouse successfully attacked one of the nestlings and forced the other to fledge. Although cameras recorded multiple visits at only 3 nests, 2 more nests at which non-cowbird predators (raccoon and garter snake) were recorded were also parasitized. Therefore, the nests must have been visited (and possibly depredated) by cowbird(s) prior to camera deployment.

\section{Camera and Age Relationships with Natural-Nest Survival}

Video cameras monitored nests for 188 and 333 days during egg and nestling periods, respectively. Besides the complete predation events for which predators were identified (Table 2), 2 additional video-monitored Song Sparrow nests and 1 video-monitored Yellow Warbler nest were depredated, but the predators were not identified due to camera malfunctions. Thus, a total of 3 Song Sparrow and 4 Yellow Warbler camera nests were completely depredated. Survival rates were higher for video- versus non-video-monitored nests; camera nests were approximately twice as likely to succeed as non-camera nests (Table 3). Unlike video-monitored nests, clutch survival 
TABLE 3. Survival rates for video-monitored and non-video-monitored nests estimated with logistic exposure models for Yellow Warblers (YEWA) and Song Sparrows (SOSP) in Mono Lake Basin riparian habitats. Models estimated daily survival rates (DSR $\pm \mathrm{SE}$ ) and these were translated into total survival rates $\left(\mathrm{TSR}=\mathrm{DSR}_{\mathrm{Egg}} \mathrm{Egg}_{\mathrm{g}}\right.$ period $\times$ $\mathrm{DSR}_{\text {Nestling }}$ Nestling_period; see text for egg and nestling periods). Models for both species included Site $\times$ Year blocking variables (there were 7 and 3 Site $\times$ Year blocks for YEWA and SOSP, respectively) and parasitism status as covariates. The YEWA model also included a binary covariate describing nest substrate (mesic vs. xeric shrub species). Residuals were overdispersed $(\hat{c}=2.4$ and 1.3 for YEWA and SOSP models, respectively), so variances were inflated accordingly

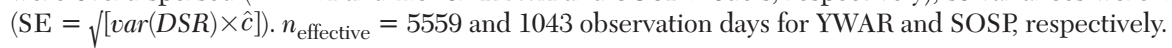

\begin{tabular}{llccc}
\hline Species & Treatment & Egg & Nestling & Total \\
\hline YEWA & Camera & $0.9913 \pm 0.0013$ & $0.9897 \pm 0.001$ & $0.805 \pm 0.140$ \\
& Non-camera & $0.9489 \pm 0.0027$ & $0.9731 \pm 0.0013$ & $0.383 \pm 0.103$ \\
SOSP & Camera & $0.9821 \pm 0.0028$ & $0.9837 \pm 0.0017$ & $0.653 \pm 0.172$ \\
& Non-camera & $0.9549 \pm 0.0024$ & $0.9725 \pm 0.0018$ & $0.391 \pm 0.115$ \\
\hline
\end{tabular}

TABLE 4. Field observations of nest predation recorded at Rush, Lee Vining, Mill, and Wilson creeks, Mono Lake Basin, California, 2000-2008.

\begin{tabular}{|c|c|}
\hline Predator species ${ }^{\mathrm{a}}$ & Observation \\
\hline Brown-headed Cowbird & $\begin{array}{l}\text { O A dead Yellow Warbler nestling was found just outside the nest within } 4 \text { days of previous } \\
\text { nest check. A cowbird egg was left in the nest. }\end{array}$ \\
\hline $\begin{array}{l}\text { Black-billed Magpie } \\
\quad \text { (Pica hudsonia) }\end{array}$ & - Observed depredating eggs from an American Robin (Turdus migratorius) nest. \\
\hline Steller's Jay & $\begin{array}{l}\text { - Observed eating eggs from a Yellow Warbler nest. } \\
\text { - Observed leaving the vicinity of a Yellow Warbler nest with eggs in bill. }\end{array}$ \\
\hline $\begin{array}{l}\text { Western Scrub-Jay } \\
\text { (Aphelocoma californica) }\end{array}$ & $\begin{array}{l}\text { Nestlings in a Yellow Warbler nest (both host and cowbird) were found pecked to death } \\
\text { but not consumed. Concurrent with this observation, } 2 \text { adult and } 2 \text { juvenile Western } \\
\text { Scrub-Jays were observed within } 20 \mathrm{~m} \text { of the nest calling for } 1.5 \mathrm{~h} \text { while multiple bird } \\
\text { species scolded and mobbed them. }\end{array}$ \\
\hline $\begin{array}{l}\text { Least chipmunk } \\
\text { (Neotamias minimus) }\end{array}$ & $\begin{array}{l}\text { - Observed leaving partially depredated magpie nest structure with eggs. The nest was } \\
\text { completely depredated sometime before the subsequent nest check. }\end{array}$ \\
\hline Garter snake & $\begin{array}{l}\text { - Observed depredating nestlings from a Song Sparrow nest. } \\
\text { - Observed depredating nestlings from a Brewer's Blackbird (Euphagus cyanocephalus) nest. } \\
\text { o Observed in a second Song Sparrow nest, from which either a cowbird egg or a } \\
\text { recently hatched cowbird nestling had been removed. } \\
\text { - Observed eating a Savannah Sparrow (Passerculus sandwichensis) nestling. }\end{array}$ \\
\hline Gopher snake & - Observed depredating nestlings from a Spotted Towhee (Pipilo maculatus) nest. \\
\hline
\end{tabular}

rates were lower than nestling survival rates for non-video-monitored nests.

\section{Direct and Indirect Observations Recorded by Field Workers}

Field observers recorded 8 direct observations implicating 2 additional predator species not recorded by video (least chipmunk and Black-billed Magpie) and 3 indirect observations suggesting one additional predator (Western Scrub-Jay; for taxonomic names, see Table 4). We directly observed 4 egg predation events by 3 predator species and 4 nestling predation events by 2 predator species, respectively. As in video records, garter snakes were most commonly observed depredating nestlings.
Additionally, 3 of 4 direct observations of egg predation were carried out by 2 corvid species (Table 3). None of the egg predators observed directly in the field were captured in video records.

\section{Predators of Artificial Nests}

Video cameras recorded 7 depredations of artificial nests by at least 4 species along Rush Creek: 4 by cowbirds and 1 each by a least chipmunk, a wren, and a Bullock's Oriole (Icterus bullockii; see Tables 2 and 4 for additional Latin names). Except for Bullock's Oriole, all of these species were confirmed predators of songbird eggs at natural nests, although none were confirmed predators of Yellow Warbler eggs. 


\section{Discussion}

\section{Predators of Songbird Nests in} Mono Lake Riparian Systems

We observed a broad array of species depredating songbird nests. Taken together, video records and direct field observations confirmed at least 10 nest-predator species, and additional evidence from indirect field observations suggested one additional species. The variety of predators identified here suggests a rich nest-predator community, comparable in diversity and composition to communities described in other riparian systems (Peterson et al. 2004, Small 2005).

As for most predator identification studies (reviewed by Weidinger 2008), our sample size was limited, so the predator list reported here is likely incomplete. We initially deployed cameras at nests with eggs; most of these nests succeeded, thereby keeping cameras occupied until later in the season when nests remaining active tended to be in the nestling stage. Video cameras therefore recorded disproportionately more nestling-period days, further reducing our sample sizes and opportunities to record egg predators. Nest survival models accounted somewhat for the potential effects of biased camera deployment. Therefore, biased deployment is unlikely to fully explain camera-related differences in predation rates, which resulted in cameras recording relatively few egg predators. In later years (2004 and after) to support other research, we only monitored Yellow Warbler nests at Rush Creek, reducing opportunity to record predators at other sites. Fortunately, field observations recorded predators at all 4 sites, including 3 egg-predator species not identified in video records. Thus, effects of video-related bias on our predator list were likely reduced by field observations. Nevertheless, given our small sample sizes, we are unlikely to have recorded all predator species in this system. In particular, we are most likely to have missed species that are camera-shy, inconspicuous to field workers (e.g., nocturnal), and only present at sites other than Rush Creek.

Although not comprehensive, our predator list likely includes the species that most commonly depredate songbird nests in this system. Unlike others with comparable sample sizes (see studies reviewed by Weidinger 2008), we could not identify a single clearly dominant predator species, although some species were recorded on multiple occasions. Our data suggest some differences between the predator species that depredate eggs and those that depredate nestlings, although some clearly depredate both. Garter snakes appear to commonly depredate nestlings but may less commonly, if ever, depredate eggs. Additionally, we observed an ermine apparently foregoing consumption of eggs and possibly the same ermine returning to depredate a nestling, suggesting that ermine may favor nestlings over eggs (for a similar case, see Pietz and Granfors 2005). Consistent with their life history and empirical evidence from other studies (Arcese et al. 1996, Hoover and Robinson 2007), cowbirds are likely important egg predators (discussed further below). As a group, corvids (Steller’s Jay, Black-billed Magpie, and Western Scrub-Jay in this system) may be important predators of both eggs and nestlings (see also Liebezeit and George 2002b, Peterson et al. 2004). We confirmed 2 rodent species to be nest predators and observed rodents, as a group, depredating both eggs and nestlings.

\section{Predator Behavior at Nests}

When visiting a nest, a predator may, for various reasons, only partially depredate the nest's contents or fail to depredate anything. Predators may be satiated by only a portion of a nest's contents, satiation being mediated by predator size, metabolism, and the mass of the nest's contents (for typical songbird clutch sizes, see Baicich and Harrison 2005). This hypothesis could explain why a garter snake in this study depredated a cowbird nestling but left a Song Sparrow nestling to fledge later. Partial predation may serve to reduce competition with neighbors for food or predator-free space, although complete predation would also serve this purpose (hypothesized to explain wren predation-Bellesisles and Picman 1986, Simons and Simons 1990). Predators may be deterred by avian parents before completely depredating nests. Specifically, predators that are small relative to the size of the avian parents may be most easily deterred. Older nestlings may flee the nest in response to a predator visit (Halupka 1998) or simply fledge before the predator discovers the nest (e.g., 1 mouse and 2 snake visits described in the results). Predators of nestlings may discover nests with eggs and leave them intact, 
only to return after hatching to depredate the nestlings (possibly explaining ermine behavior). Certain species may visit nests to obtain information on reproductive status of heterospecifics (e.g., the nonpredatory visit by a cowbird to a Yellow Warbler nest; consider also observed behavior by other speciesForsman and Thomson 2008). Finally, partial predation observed here could result from neophobic or camera-shy predators discovering cameras after initiating predation. Further examination of when and why predators partially depredate nests would clarify predatorspecific impacts on avian nest survival and fitness here and elsewhere (see also Small 2005).

With respect to egg predation, we mainly observed cowbirds partially depredating clutches, although in one case, the entire host clutch was destroyed. Cowbirds may eject host eggs to enhance incubation efficiency (Sealy 1992, Peer and Bollinger 2000) or to procure optimal provisioning rates for their nestlings (Kilner et al. 2004, Astie and Reboreda 2009). Consistent with these hypotheses, we observed cowbirds depredating host eggs but never parasitic eggs. Partial predation of parasitized Yellow Warbler clutches by cowbirds likely explains why they were smaller $(n=90, \bar{x}=3.19$ host eggs) than nonparasitized clutches $(n=119, \bar{x}$ $=3.72$ eggs, $t_{207}=4.2, P<0.001$ ). Cowbirds may also completely depredate nonparasitized nests either to create new parasitic opportunities ("farming hypothesis"-Arcese et al. 1996, Hoover and Robinson 2007) or to "retaliate" in response to hosts' rejection of parasitic eggs ("mafia hypothesis"-Hoover and Robinson 2007). Although we did not definitively observe such behavior here (see possible case in Table 3 ), a separate analysis did find indirect evidence in the form of higher complete predation rates for nonparasitized nests relative to parasitized nests (Latif et al. in press; for the significance of this pattern, see Arcese et al. 1996; Hoover and Robinson 2007). The intensity of cowbird predation is likely host-specific and dependent upon ecological circumstances (Ortega 1998, Peer 2006). Footage of a cowbird visiting but not depredating a nonparasitized Yellow Warbler nest suggests that cowbirds are selective of which nests to depredate. Since cowbirds are capable of strongly affecting host demographics (Arcese et al. 1996, Zanette et al. 2007, Kelly and Peter 2008), quantification of the cowbird predation threat in this system would inform management of sensitive species (e.g., Willow Flycatchers [Empidonax traillii]_McCreedy and Heath 2004; Yellow Warblers-Heath 2008).

\section{Relevance of Artificial Nests for Studying Songbird Egg Predation Patterns}

Six of the 7 predators of artificial nests were known egg predators, so artificial-nest data are relevant for studying the behavior and habitat relationships for at least some species that impact songbird egg survival. Furthermore, the relatively high egg-predation rates measured for at least 2 species common to this system suggest that egg-predation rates are an important component of overall nest survival. Because only 2 egg-predator species were identified for Yellow Warblers, we could not verify the specific relevance of artificial-nest data to this species. Since clutch survival rates were much lower at non-video-monitored nests, we likely failed to identify important predators of Yellow Warbler eggs, but species observed depredating eggs of other species are likely culprits. In addition to their observed nest predation in this study, Bullock's Orioles also depredated artificial nests in another study (Purcell and Verner 1999), but they were never reported depredating natural nests across a wide range of camera studies (see reviews by Thompson 2007, Richardson et al. 2009). Predation of artificial nests by Bullock's Orioles may diminish the biological relevance of the resulting data, but they did not appear to be an important predator of artificial nests used to study nest predation in this system.

\section{Implications for Management, Understanding} Predation Patterns, and Future Research

Identification of the nest predators that principally determine songbird nest survival can provide critical information for guiding conservation and management strategies. For example, temporary removal of principal predators may help boost populations on the brink of extirpation (e.g., cowbird removal rescued Least Bell's Vireo [Vireo bellii pusillus], although not Southwestern Willow Flycatcher [Empidonax traillii extimus]_Kus and Whitfield 2005), assuming such predators can be identified, their contributions to nest failure are additive, and there are no confounding interactions among predators. Alternatively, and probably more often, identification of 
important predators can provide insight into causes of spatiotemporal predation patterns (e.g., Schmidt et al. 2006, Weatherhead et al. 2010). Such insights are critical for designing management strategies (e.g., ecosystem restoration) likely to benefit avian fitness (Lindell 2008). This study suggests that no single predator species is likely to be principally important in limiting songbird nest survival and fitness in this system. Managers and avian ecologists may therefore need to focus research on a suite of predators to fully understand the factors determining songbird nest survival (e.g., Benson et al. 2010). Lending additional support to this notion, video data identified several nests whose fates were determined by multiple predator species. Researchers and managers should also recognize the potential for spatiotemporal heterogeneity in the relative importance of particular nest predators, even at the relatively restricted spatial and temporal scales of this study. For instance, Steller's Jays occurred principally along creeks with a substantial cottonwood and Jeffery pine (Pinus jeffreyi) canopy (Mill and Lee Vining creeks; PRBO unpublished data), and Black-billed Magpies have largely disappeared from Rush Creek in recent years (2008-2011; C. McCreedy and PRBO unpublished data).

Diverse predator communities may benefit birds by exposing them to predators with a variety of hunting strategies and microhabitatuse patterns. Such situations may favor plasticity in predator avoidance strategies (e.g., Eggers et al. 2006, Peluc et al. 2008, Latif et al. 2012), potentially allowing birds to adapt to changes in predator communities resulting from climate change or other changes to the environment. Even where predators are diverse, however, a variety of species can exhibit common behavioral patterns. A prominent microhabitat predation pattern experienced by Yellow Warblers in this system (higher predation rates in willow versus non-willow habitats) reflected habitat relationships with at least 2 different predator types (avian and rodent predators-Latif et al. 2011). If birds become habituated to such patterns, environmental change could shift predator behavior too quickly, in which case predator avoidance strategies may become maladaptive (e.g., "ecological traps"-Latif et al. 2011).

\section{ACKNOWLEDGMENTS}

J. Rotenberry, L. Nunney, K. Weidinger, P. Coates, and 6 anonymous reviewers provided comments on early versions of this manuscript. L. Culp, R. Hirsch-Jacobson, C. McCreedy, S. Moss, C. Tonra, T. Stage, R. McGillicuddy, and numerous other PRBO biologists and volunteer field workers found and monitored nests and transported video equipment. Advanced Energy Group, the California Department of Fish and Game, Inyo National Forest, the Bureau of Land Management, the National Fish and Wildlife Foundation, the Mono Lake Committee, and USDA Forest Service Region 5 Partners in Flight provided financial and logistical support and equipment. The Los Angeles Department of Water and Power provided access to city lands along Rush, Lee Vining, and Mill creeks. J. Rochester, R. Kapur, and F. Johnson donated finch eggs for artificial nests. G. Geupel provided videotapes. The UC Riverside Biology Department, the Center for Conservation Biology, and the Rocky Mountain Research Station (USDA Forest Service) all supported Q. Latif during his dissertation research and/or manuscript preparation. S.K. Heath was supported by the National Science Foundation through a Graduate Research Fellowship during manuscript preparation. This is PRBO Contribution \#1876.

\section{Literature Cited}

Aguilar, T.M., R.I. Dias, A.C. Oliveira, and R.H. Macedo. 2008. Nest-site selection by Blue-black Grassquits in a Neotropical savanna: do choices influence nest success? Journal of Field Ornithology 79:24-31.

Arcese, P., J.N.M. Smith, and M.I. Hatch. 1996. Nest predation by cowbirds and its consequences for passerine demography. Proceedings of the National Academy of Sciences USA 93:4608-4611.

Astie, A.A., And J.C. ReboredA. 2009. Function of egg punctures by Shiny Cowbirds in parasitized and nonparasitized Creamy-bellied Thrush nests. Journal of Field Ornithology 80:336-343.

Baicich, P.J., And C.J.O. Harrison. 2005. Field guide to the nests, eggs, and nestlings of North American birds. Princeton University Press, Princeton, NJ.

Bellesisles, J.C., and J. Picman. 1986. House Wren nest-destroying behavior. Condor 88:190-193.

Benson, T.J., J.D. BRown, AND J.C. Bednarz. 2010. Identifying predators clarifies predictors of nest success in a temperate passerine. Journal of Animal Ecology 79:225-234.

Burnham, K.P., AND D.R. Anderson. 2002. Model selection and multimodel inference: a practical information-theoretic approach. Springer-Verlag, New York, NY. 
Clark, M.E., And T.E. MaRTin. 2007. Modeling tradeoffs in avian life history traits and consequences for population growth. Ecological Modeling 209:110-120.

Coates, P.S., and D.J. Delehanty. 2010. Nest predation of Greater Sage-Grouse in relation to microhabitat factors and predators. Journal of Wildlife Management 74:240-248.

Dinsmore, S.J., G.C. White, and F.L. KnOpf. 2002. Advanced techniques for modeling avian nest survival. Ecology 83:3476-3488

Eggers, S., M. Griesser, M. Nystrand, and J. Ekman. 2006. Predation risk induces changes in nest-site selection and clutch size in the Siberian Jay. Proceedings of the Royal Society Biological Sciences Series B 273:701-706.

Filliater, T.S., R. BReitwisch, and P.M. Nealen. 1994 Predation on Northern Cardinal nests: does choice of nest site matter? Condor 96:761-768.

Fitzhugh, T.W., AND B.D. Richter. 2004. Quenching urban thirst: growing cities and their impacts on freshwater ecosystems. Bioscience 54:741-754.

Forsman, J.T., AND R.L. ThOmson. 2008. Evidence of information collection from heterospecifics in cavitynesting birds. Ibis 150:409-412.

HalupKa, K. 1998. Partial nest predation in an altricial bird selects for the accelerated development of young. Journal of Avian Biology 29:129-133.

Heath, S.K. 2008. Yellow Warbler (Dendroica petechia). Pages 332-339 in W.D. Shuford and T. Gardali, editors, California bird species of special concern: a ranked assessment of species, subspecies, and distinct populations of birds of immediate conservation concern in California. Western Field Ornithologists, Camarillo, CA, and California Department of Fish and Game, Sacramento, CA.

Heath, S.K., M.A. Palladini, and S. Prentice. 2006a. Breeding bird census 2001: irrigated mixed willow riparian. Bird Populations 7:96.

Heath, S.K., C. McCreedy, and Q.S. Latif. 2006b. Breeding bird census 2001: recovering mixed willowblack cottonwood riparian I. Bird Populations 7:97.

Heath, S.K., M.A. Palladini, and S. Prentice. 2006c. Breeding bird census 2001: recovering mixed willowblack cottonwood riparian II. Bird Populations 7: 97-98.

Heath, S.K., C. McCreedy, and Q.S. Latif. 2006d. Breeding bird census 2001: remnant black cottonwood riparian forest. Bird Populations 7:98-99.

Hoover, J.P., AND S.K. RoBInson. 2007. Retaliatory mafia behavior by a parasitic cowbird favors host acceptance of parasitic eggs. Proceedings of the National Academy of Sciences 104:4479-4483.

Kelly, J.J., AND A. Peter. 2008. Consequences of parasite invasion and land use on the spatial dynamics of host populations. Journal of Applied Ecology 45:1180-1188.

Kilner, R.M., J.R. Madden, And M.E. Hauber. 2004 Brood parasitic cowbird nestlings use host young to procure resources. Science 304:877-879.

Knopf, F.I., R.R. Johnson, T. Rich, F.B. SAmson, and R.C. Szaro. 1988. Conservation of riparian ecosystems in the United States. Wilson Bulletin 100:272-284.

Kus, B.E., AND M.J. WhitFIELD. 2005. Parasitism, productivity, and population growth: response of Least Bell's Vireos (Vireo bellii pusillus) and Southwestern Willow Flycatchers (Empidonax traillii extimus) to cowbird (Molothrus spp.) control. Ornithological Monographs 57:16-27.
LAHTI, D.C. 2009. Why we have been unable to generalize about bird nest predation. Animal Conservation $12: 279-281$

Lariviere, S., AND F. MEssier. 1997. Characteristics of waterfowl nest depredation by the striped skunk (Mephitis mephitis): can predators be identified from nest remains? American Midland Naturalist 137: 393-396.

Latif, Q.S., S.K. Heath, and J.T. Rotenberry. 2011. An 'ecological trap' for yellow warbler nest microhabitat selection. Oikos 120:1139-1150.

2012. How avian nest site selection responds to predation risk: testing an 'adaptive peak hypothesis.' Journal of Animal Ecology 81:127-138.

In press. Effects of parents and Brown-headed Cowbirds (Molothrus ater) on nest predation risk for a songbird. Ecology and Evolution.

Liebezeit, J.R., AND T.L. GEORGE. 2002a. Nest predators, nest-site selection, and nesting success of the Dusky Flycatcher in a managed ponderosa pine forest. Condor 104:507-517.

$2002 \mathrm{~b}$. A summary of predation by corvids on threatened and endangered species in California and management recommendations to reduce corvid predation. California Department of Fish and Game, Species Conservation and Recovery Program Report 2002-02, Sacramento, CA. 103 pp.

LimA, S.L. 2009. Predators and the breeding bird: behavioral and reproductive flexibility under the risk of predation. Biological Reviews 84:485-513.

LINDELL, C.A. 2008. The value of animal behavior in evaluations of restoration success. Restoration Ecology 16:197-203.

MajOR, R.E., AND C.E. Kendal. 1996. The contribution of artificial nest experiments to understanding avian reproductive success: a review of methods and conclusions. Ibis 138:298-307.

MaRTIN, T.E. 1989. Breeding productivity considerations: what are the appropriate habitat features for management? Pages 455-473 in Manomet Symposium. Arkansas Cooperative Fish and Wildlife Research Unit, U.S. Fish and Wildlife Service.

MCCReedy, C., AND S.K. Heath. 2004. Atypical Willow Flycatcher nesting sites in a recovering riparian corridor at Mono Lake, California. Western Birds 35:197-209.

Moore, R.P., AND D. Robinson. 2004. Artificial bird nests, external validity, and bias in ecological field studies. Ecology 85:1562-1567.

OHMART, R.D. 1994. The effects of human-induced changes on the avifauna of western riparian habitats. Studies in Avian Biology 15:273-285.

ORTEGA, C.P. 1998. Cowbirds and other brood parasites. University of Arizona Press, Tucson, AZ.

PEER, B.D. 2006. Egg destruction and egg removal by avian brood parasites: adaptiveness and consequences. Auk 123:16-22.

PeER, B.D., And E.K. Bollinger. 2000. Why do female Brown-headed Cowbirds remove host eggs? A test of the incubation efficiency hypothesis. Pages 187192 in J.N.M. Smith, T.L. Cook, S.I. Rothstein, S.K. Robinson, and S.G. Sealy, editors, Ecology and management of cowbirds and their hosts. University of Texas Press, Austin, TX.

Peluc, S., S.T. Sillett, J.T. Rotenberry, and C.K. GhaLAMBOR. 2008. Adaptive phenotypic plasticity in an island songbird exposed to novel predation risk. Behavioral Ecology 19:830-835. 
Peterson, B.L., B.E. Kus, and D.H. Deutschman. 2004. Determining nest predators of the Least Bell's Vireo through point counts, tracking stations, and video photography. Journal of Field Ornithology 75:89-95.

Pietz, P.A., AND D.A. Granfors. 2000. Identifying predators and rates of grassland passerine nests using miniature video cameras. Journal of Wildlife Management 64:71-87.

Pietz, P.J., AND D.A. Granfors. 2005. Parental nest defense on videotape: more reality than "myth." Auk 122:701-705.

Powell, L.A. 2007. Approximating variance of demographic parameters using the delta method: a reference for avian biologists. Condor 109:949-954.

Purcell, K.L., AND J. Verner. 1999. Nest predators of open and cavity nesting birds in oak woodlands. Wilson Bulletin 111:251-256.

Richardson, T.W., T. Gardali, and S.H. Jenkins. 2009. Review and meta-analysis of camera effects on avian nest success. Journal of Wildlife Management 73: 287-293.

RiCKLEFS, R.E. 1969. An analysis of nesting mortality in birds. Smithsonian Contributions to Zoology 9:1-48.

SAAB, V.A., C.E. Bock, T.D. RICH, AND D.S. DobKIN. 1995 Livestock grazing effects in western North America. Pages 311-354 in T.E. Martin and D.M. Finch, editors, Ecology and management of Neotropical migratory birds: a synthesis and review of critical issues. Oxford University Press, New York, NY.

SAether, B.-E., AND O. BAKKe. 2000. Avian life history variation and contribution of demographic traits to the population growth rate. Ecology 81:642-653.

Santisteban, L., K.E. Sieving, and M.L. Avery. 2002. Use of sensory cues by fish crows Corvus ossifragus preying on artificial bird nests. Journal of Avian Biology 33:245-252.

Schmidt, K.A., J.R. GoheEn, and R. Naumann. 2001. Incidental nest predation in songbirds: behavioral indicators detect ecological scales and processes. Ecology 82:2937-2947.

SCHMIDT, K.A., R.S. OstFeld, AND K.N. SMYTH. 2006. Spatial heterogeneity in predator activity, nest survivorship, and nest-site selection in two forest thrushes. Oecologia 148:22-29.

Schmidt, K.A., And C.J. Whelan. 1999. Nest predation on woodland songbirds: when is nest predation density dependent? Oikos 87:65-74.

SEALY, S. 1992. Removal of Yellow Warbler eggs in association with cowbird parasitism. Condor 94:40-54.

Shaffer, T.L. 2004a. Logistic-exposure analyses of nest survival. Northern Prairie Wildlife Research Center Online, Jamestown, ND [Version 28AUG2008]. Available from: http://www.npwrc.usgs.gov/resource/ birds/nestsurv/index.htm 2004b. A unified approach to analyzing nest success. Auk 121:526-540.

SimONS, L.S., AND L.H. SimONS. 1990. Experimental studies of nest-destroying behavior by Cactus Wrens. Condor 92:855-860.

SMALL, S.L. 2005. Mortality factors and predators of Spotted Towhee nests in the Sacramento Valley, California. Journal of Field Ornithology 76:252-258.

Sperry, J.H., D.A. Cimprich, R.G. PEaK, and P.J. WeathERHEAD. 2009. Is nest predation on two endangered bird species higher in habitats preferred by snakes? Ecoscience 16:111-118.

Stake, M.M., AND D.A. Cimprich. 2003. Using video to monitor predation at Black-capped Vireo nests. Condor 105:348-357.

STINE, S. 1995. Restoration of degraded riparian, wetland, and deltaic environments on Mill Creek, Mono County, California. Report to Ducks Unlimited, Hornocker Wildlife Research, U.S. Forest Service and Los Angeles Department of Water and Power. Mono Lake Research Library, Box 29, Lee Vining, CA 93541.

Stine, S., D. Gaines, and P. Vorster. 1984. Destruction of riparian systems due to water development in the Mono Lake watershed. Pages 528-533 in R.E. Warner and K.M. Hendrix, editors, California riparian systems: ecology, conservation, and management. University of California Press, Berkeley, CA.

Thompson, F.R. 2007. Factors affecting nest predation on forest songbirds in North America. Ibis 149:98-109.

Thompson, F.R., AND D.E. Burhans. 2004. Differences in predators of artificial and real songbird nests: evidence of bias in artificial nest studies. Conservation Biology 18:373-380.

Weatherhead, P.J., G.L.F. Carfagno, J.H. Sperry, J.D. BRAWN, AND S.K. Robinson. 2010. Linking snake behavior to nest predation in a Midwestern bird community. Ecological Applications 20:234-241.

WEIDINGER, K. 2002. Interactive effects of concealment, parental behaviour and predators on the survival of open passerine nests. Journal of Animal Ecology 71:424-437.

2008. Identification of nest predators: a sampling perspective. Journal of Avian Biology 39:640-646.

Wilson, R.R., AND R.J. CoOper. 1998. Acadian Flycatcher nest placement: does placement influence reproductive success? Condor 100:673-679.

Zanette, L., D.T. Haydon, J.N.M. Smith, M.J. TaitT, And M. Chinchy. 2007. Reassessing the cowbird threat. Auk 124:210-223.

Received 2 March 2012 Accepted 4 June 2012 